\title{
Increased tumour necrosis factor $\alpha$ production in mesenteric lymph nodes of cirrhotic patients with ascites
}

\author{
J Genescà, R Martí, F Rojo, F Campos, V Peribáñez, A Gónzalez, L Castells, \\ C Ruiz-Marcellán, C Margarit, R Esteban, J Guardia, R Segura
}

Gut 2003;52:1054-1059

Background: Cytokines produced in mesenteric lymph nodes of cirrhotic rats with bacterial translocation may participate in circulatory alterations of cirrhosis.

Aim: To investigate whether cirrhotic patients present an increased local generation of cytokines in mesenteric lymph nodes.

Methods: Mesenteric lymph nodes from 26 cirrhotic and 10 control patients were assessed for tumour necrosis factor $\alpha$ (TNF) and interleukin 6 mRNA and protein expression by competitive reverse transcription-polymerase chain reaction, and by enzyme immunoassay and immunohistochemistry, respectively.

See end of article for authors' affiliations

Correspondence to: Dr J Genesca, Liver Unit Department of Internal Medicine, Hospital Universitari Vall d'Hebron, Passeig Vall d'Hebron 119-129, 08035 Barcelona, Spain; igenesca@hg.vhebron.es

Results: Interleukin 6 levels were not different between cirrhotics and controls. Protein and mRNA TNF levels in mesenteric lymph nodes from cirrhotics were higher than in controls $(p<0.05)$. Tissue expression of TNF by immunohistochemistry was more abundant in cirrhotics. Ascitic patients showed higher TNF levels (47 (34-54) pg/mg protein) than patients without ascites (18 (17-25) pg/mg protein) $(\mathrm{p}<0.001)$. Elevated TNF levels (>28 pg/mg protein) in cirrhotics were associated with a higher ChildPugh score, the antecedent of ascites, a lower prothrombin rate, and higher bilirubin and blood TNF levels. The strongest association, confirmed by multivariate analysis, was with the presence of ascites $(p<0.001)$. Bacterial infections after transplantation, mainly by enteric bacteria, were only detected in patients with high TNF levels in mesenteric lymph nodes (33\% of patients; $p=0.05$ ).

Conclusion: Patients with advanced liver cirrhosis, and especially with ascites, have increased local production of TNF in mesenteric lymph nodes that, in common with experimental cirrhosis, may also be induced by bacterial translocation.

S planchnic arterial vasodilation seems to be a major contributor to the pathogenesis of the hyperdynamic circulatory syndrome in liver cirrhosis. ${ }^{12}$ These haemodynamic alterations tend to worsen in parallel with deterioration of liver function, the hepatorenal syndrome being the final event of this process. Among many mediators, nitric oxide (NO) and tumour necrosis factor $\alpha$ (TNF) have both been implicated in the pathogenesis of these circulatory alterations. ${ }^{3-5}$ An initial hypothesis suggested that bacterial products would activate cytokine synthesis (TNF and others) and account for haemodynamic changes in advanced cirrhosis by stimulating expression of inducible NO synthase (iNOS). ${ }^{\circ}$ However, many reports indicate that iNOS activation is minimal in cirrhosis and, in contrast, the endothelial form of NOS (eNOS) has been consistently found to be upregulated both in animal models and humans with liver cirrhosis. ${ }^{5}$

TNF is a cytokine that it is mainly released by mononuclear cells in response to inflammatory stimuli. ${ }^{7}$ The gut and its associated lymphoid tissue, including the mesenteric lymph nodes (MLN), has been shown to produce TNF in response to bacterial translocation induced by intestinal injury caused by zymosan or shock injury. ${ }^{8}$ More recently, increased TNF production by MLN with bacterial translocation was detected in cirrhotic rats. ${ }^{10}$ This locally produced TNF may contribute to splanchnic vasodilation by enhancing eNOS derived NO release. Interleukin 6 (IL-6), another proinflammatory cytokine, is also involved in the pathogenesis of the circulatory alterations of liver cirrhosis. ${ }^{11}{ }^{12}$

We designed this study to determine whether patients with liver cirrhosis also show increased local production of cytokines in MLN and to investigate the clinical and haemodynamic implications of this phenomenon.

\section{PATIENTS AND METHODS} Study population

Twenty six patients with liver cirrhosis (mean age 54 (11) years; 57\% males) undergoing liver transplantation were included in the study. The aetiology of cirrhosis was related to hepatitis $\mathrm{C}$ virus infection in 11 patients, alcohol consumption in seven, alcoholism and viral infection in five, and other aetiologies in three patients. Hepatocellular carcinoma was present in six patients $(23 \%)$. Thirteen patients had ascites and three had renal failure at the time of transplantation. Oesophageal varices were detected by endoscopy in 20 patients $(77 \%)$. Twelve patients were receiving $\beta$-blocker therapy for prophylaxis of variceal bleeding and nine were taking norfloxacin for selective intestinal decontamination. Apart from norfloxacin intake, no antibiotics were administered to patients for at least one month prior to surgery. At the time of surgery, six patients were classified as Child-Pugh class A, 10 as class B, and 10 as class C.

Immediately before surgery, prophylactic antibiotics (ampicillin and cefotaxime) were administered to all patients. Haemodynamic data were obtained during phase I of liver transplantation before surgical incision and after induction of anaesthesia with a combination of propofol, fentanyl citrate, and atracurium. Specific measurements of right heart pressures were performed through a Swan-Ganz catheter.

Abbreviations: NO, nitric oxide; TNF, tumour necrosis factor $\alpha$; iNOS, inducible nitric oxide synthase; eNOS, endothelial nitric oxide synthase; $M L N$, mesenteric lymph nodes; IL-6, interleukin 6; PCR, polymerase chain reaction; ICS, internal calibration standard; EIA, enzyme immunoassays; GAPDH, glyceraldehyde-3-phosphate dehydrogenase. 
Cardiac output was determined by thermodilution and arterial pressure by arterial catheter measurements. Portal venous pressure was measured with a catheter placed in the portal vein through a branch of the superior mesenteric vein. Portal blood flow was determined by laser Doppler flowmetry.

Ten patients without cirrhosis were included in the control group (mean age 50 (10) years; $50 \%$ males). Three of these controls were organ donors who had not been receiving antibiotics or vasoactive drugs during their stay in the intensive care unit prior to organ donation. Causes of death for these three patients were head trauma, haemorrhagic stroke, and asthmatic status. The other seven controls underwent laparotomy for different non-malignant and non-infectious conditions (two ovarian cysts, one colonic adenoma, and four hepatectomies for benign tumours and conditions). Prophylactic antibiotics were administered to these patients immediately before surgery. This protocol was approved by the ethics committee of our hospital and written informed consent was obtained from all patients and controls before surgery.

\section{Lymph node sampling}

Following laparotomy and before initiating the surgical procedure, a MLN from the terminal ileal mesenteric area was obtained (30 (10) minutes after laparotomy) and divided into several fragments. One was fixed in formalin and taken to the pathology laboratory for further processing. If the pathological examination did not demonstrate a typical lymph node morphology, the patient was excluded from the study. In fact, that was the case in four cirrhotic patients not included in the study. The other pieces obtained were immediately frozen in liquid nitrogen and kept at $-80^{\circ} \mathrm{C}$. In addition, in 13 cirrhotic patients, once the hepatic hilium was dissected, another lymph node from this area was obtained and processed as described.

\section{Enzyme immunoassays (EIA)}

Lymph node fragments were mechanically homogenised in buffer ( $10 \mu \mathrm{l}$ per $1 \mathrm{mg}$ of tissue) at $1000 \mathrm{rpm}$ for 10 minutes at $4^{\circ} \mathrm{C}$. The buffer was Tris $\mathrm{HCl} 100 \mathrm{mmol} / \mathrm{l}, \mathrm{pH} 7.45$, containing EDTA $2 \mathrm{mmol} / \mathrm{l}$, phenylmethylsulphonyl fluoride $1 \mathrm{mmol} / \mathrm{l}$, and sucrose $150 \mathrm{mmol} / \mathrm{l}$. Homogenates were centrifuged at $10000 \mathrm{rpm}$ for 10 minutes at $4^{\circ} \mathrm{C}$ and the supernatants kept at $-80^{\circ} \mathrm{C}$ until TNF and IL- 6 levels were measured by EIA tests with standards calibrated against WHO international standards (Roche Diagnostics, Germany). TNF and IL-6 concentrations were normalised to the homogenate protein content, measured by the benzethonium chloride method, to correct for differences among extraction yields. Plasma samples obtained at the same time of transplantation were also assessed for TNF levels by EIA.

\section{Reverse transcription-polymerase chain reaction}

For total RNA extraction, tissue samples were homogenised in phenol and guanidine isothiocyanate. Aqueous and organic phases were separated by adding chloroform, and RNA was precipitated from the aqueous phase with isopropyl alcohol. This procedure was repeated twice to avoid DNA contamination in the isolated RNA preparation. The final pellet was washed three times with $75 \%$ ethanol and RNA was dissolved in $100 \mu \mathrm{l}$ of RNase free water. Total RNA was quantified spectrophotometrically, and an absorbance ratio (260/280 nm) higher than 1.7 was accepted as good quality RNA preparation. mRNA was isolated from total RNA using biotin labelled oligo (dT) and streptavidin magnetic particles (mRNA isolation kit for tissue; Boehringer Mannheim, Germany). cDNA was synthesised from mRNA with a primer poly $(\mathrm{dT})_{15}$ $16 \mu \mathrm{mol} / \mathrm{l}$. Retrotranscription was initiated by adding RNase inhibitor $1.36 \mathrm{kU} / \mathrm{ml}$, dNTP ( $1 \mathrm{mmol} / \mathrm{l} \mathrm{each}$ ), $2.5 \mathrm{U} / \mathrm{ml}$ of AMV reverse transcriptase, and reverse transcriptase buffer. All concentrations are final concentrations in the reaction

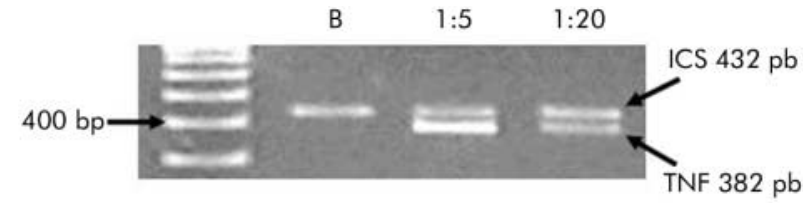

Figure 1 Agarose gel electrophoresis of competitive polymerase chain reaction for tumour necrosis factor $\alpha$ (TNF) mRNA. From left to right: molecular weight marker, blank amplification with the internal calibration standard (ICS) band, competitive amplification of ICS, and TNF cDNA at two different dilutions of cDNA.

mixture which was incubated for one hour at $42^{\circ} \mathrm{C}$ and then at $95^{\circ} \mathrm{C}$ for two minutes.

The CytoXpress TNF- $\alpha$ and IL-6 kits (Biosource International, California, USA) were used for competitive polymerase chain reaction (PCR) amplification and quantitation of cytokine mRNA. In this procedure, an internal calibration standard (ICS), with primer binding sites identical to the cytokine cDNA, is coamplified with the target DNA. Primers, one of which is biotinylated, are incorporated during PCR into both the ICS and cytokine cDNA. Following PCR, amplicons are denatured and hybridised to either ICS or cytokine sequence specific capture oligonucleotides prebound to microtitre wells. PCR was carried out in a $50 \mu \mathrm{l}$ mixture containing dNTPs $(200 \mu \mathrm{mol} / \mathrm{l}$ each), primer pairs $(500 \mathrm{nmol} / \mathrm{l})$, $\mathrm{MgCl}_{2}$ buffer $\left(\mathrm{Mg}^{2+} 1.5 \mathrm{mmol} / \mathrm{l}\right)$, a mix of Taq DNA and Pwo DNA polymerases $(26.25 \mathrm{U} / \mathrm{ml})$ (Expand High Fidelity PCR System; Roche, Germany), ICS (20 copies/ $\mu \mathrm{l}$ ), and $2.5 \mu \mathrm{l}$ of the target cDNA. Target cDNA was amplified at various dilutions to assure effective competition with the ICS. Thermal cycler conditions were as follows: an initial denaturing step at $95^{\circ} \mathrm{C}$ for 2.5 minutes, and 30 cycles of denaturation $\left(95^{\circ} \mathrm{C}\right.$, one minute), annealing $\left(55^{\circ} \mathrm{C}\right.$, one minute), and extension $\left(72^{\circ} \mathrm{C}\right.$
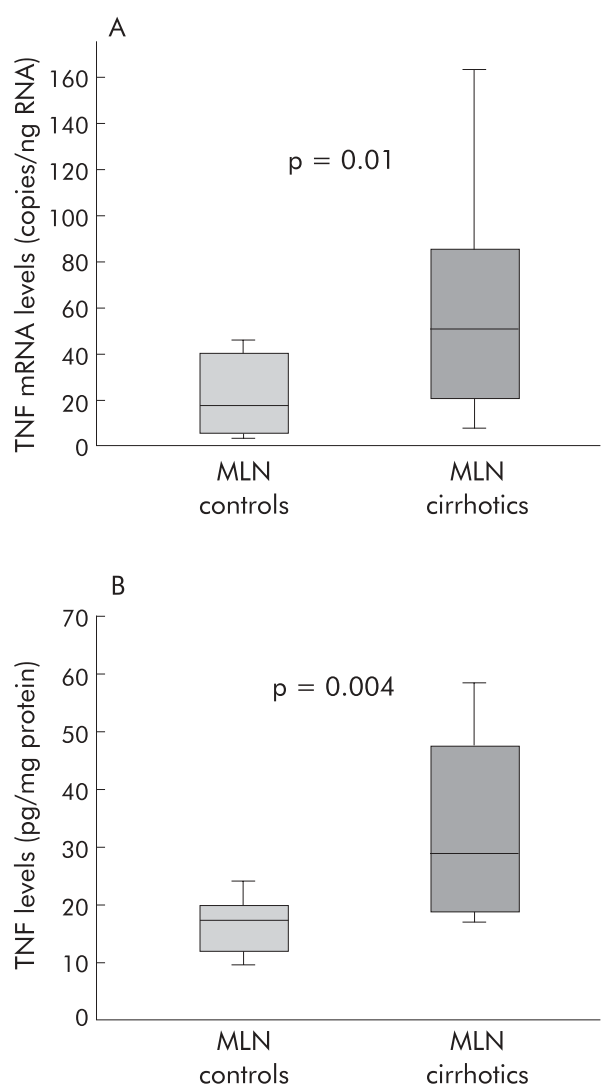

Figure 2 Comparison of tumour necrosis factor $\alpha$ (TNF) mRNA levels $(A)$ and TNF levels (B) in mesenteric lymph nodes (MLN) from controls and cirrhotic patients. 

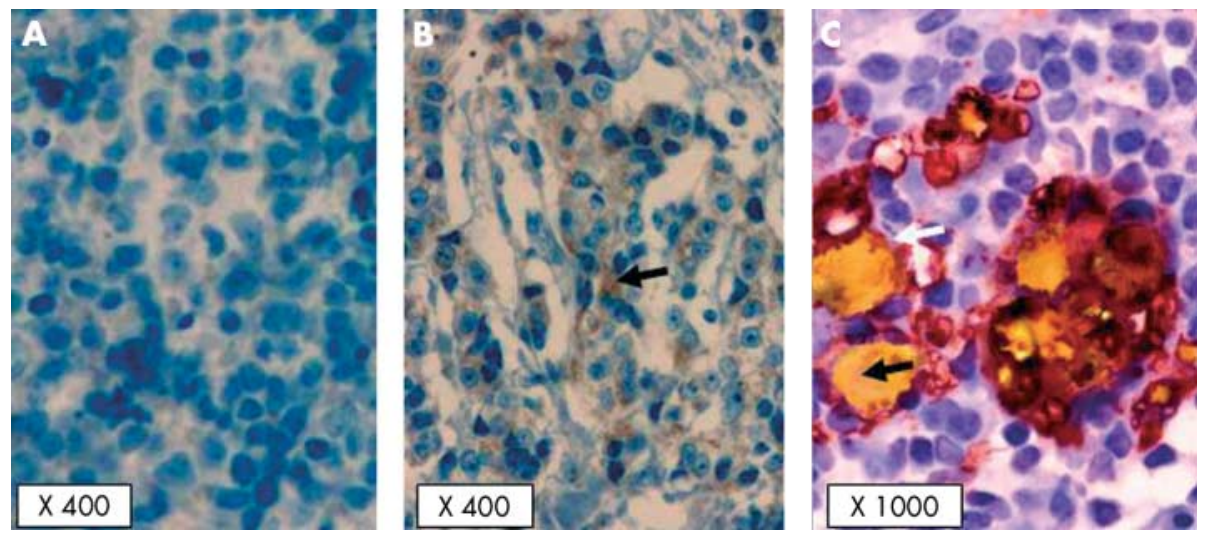

Figure 3 Tumour necrosis factor $\alpha$ (TNF) expression by immunohistochemistry in mesenteric lymph nodes from a control patient (A) and a cirrhotic patient (B). The brownish cytoplasmic staining around the nuclei of mononuclear cells corresponds to TNF expression (arrow in (B)). (C) Double immunostaining showing coexpression of cytoplasmic TNF (yellow staining, black arrow) and membrane CD68, a macrophage marker (red staining, white arrow).

one minute), with a final extension step at $72^{\circ} \mathrm{C}$ for 10 minutes. To check the integrity of RNA extraction and cDNA synthesis, the ubiquitous enzyme glyceraldehyde-3phosphate dehydrogenase (GAPDH) was amplified with primer pairs supplied in the kit under the above mentioned conditions. ICS, cytokine cDNA, and GAPDH amplicons, with sizes of 382, 432, and 382 bp, respectively, were visually analysed in a $1.5 \%$ agarose gel stained with ethidium bromide (fig l). Cytokine cDNA dilution with a band intensity visibly equivalent to ICS was used for posterior quantitation in the microtitre plate. For microplate quantitation, the instructions of the kit were followed. In short, absorbance values obtained from adding streptavidin-horseradish peroxidase to the microtitre wells containing the captured ICS and cytokine cDNA were used to calculate the final number of cytokine cDNA copies. Finally, the number of cDNA cytokine copies was normalised to the amount of total RNA extracted, to correct for differences among extraction yields.

\section{Immunohistochemistry}

MLN samples from selected cirrhotic patients with high TNF levels $(n=4)$ and controls with low TNF levels $(n=3)$ were analysed for TNF tissue expression. Specimens fixed in 10\% buffered neutral formalin were dehydrated and paraffin embedded under vacuum. Immunostaining was performed using $4 \mu \mathrm{m}$ tissue sections placed on positively charged glass slides. After deparaffinisation in xylene and degraded alcohols, target retrieval for TNF was performed in $10 \mathrm{mM}$ citrate buffer solution, ph 6 , for three minutes in a pressure cooker. Following epitope retrieval, endogenous peroxidase was blocked by immersing the sections in $0.03 \%$ hydrogen peroxide for five minutes. Incubations with primary polyclonal antibody against human TNF (R\&D Systems Inc, Minneapolis, Minnesota, USA) was performed at room temperature for two hours ( $1 / 50$ dilution). Immunodetection of antigen was carried out with biotinylated antigoat immunoglobulin for 20 minutes at room temperature, and then with horseradish peroxidase labelled streptavidin complexes for 20 minutes at room temperature (Super Sensitive Immunodetection System; BioGenex, San Ramon, California, USA). Sections were visualised with 3,3'-diaminobenzidine as a chromogen for five minutes and counterstained with Mayer's haematoxylin. Sections from lymph node biopsies were incubated with negative control polyclonal immunoglobulin instead of primary antibody and used as negative controls. To score a mononuclear cell as positive, cytoplasmic staining with a partial membrane pattern was required. The intensity of staining was scored from 0 to 3 to evaluate the degree of expression of TNF.

To identify which lymph node cells were implicated in TNF production, a double immunostaining was performed. In this case, TNF was visualised using a different chromogen (DAB chromogen; Chemicon, Tenecula, California, USA) that gives a yellowish staining. A monoclonal anti-CD68 at 1/100 dilution (Clone KPl; Dako Corporation, Carpinteria, Califonia, USA) was used to identify macrophages in the lymph nodes. The secondary antibody was a rabbit antimouse antibody (EnVision; Dako), and the Vulcan Fast Red (Biocare Medical, Walnut Creek, Califonia, USA) was used as a chromogen giving a membrane reddish staining.

\section{Statistics}

Results are expressed as median (25th-75th percentiles). Frequency data were compared using the $\chi^{2}$ test or Fischer's exact test when necessary. The Mann-Whitney U test was used for comparison of quantitative data between groups. Data in the figures are represented as box and whisker plots. The extremities of the diagram indicate 10th to 90th percentiles and the ends of the box the lower and the upper quartiles. When patients with low and high MLN TNF levels (using the median TNF values as the cut off point) were compared, data were expressed as mean (SD) as a normal distribution was observed, and parametric tests were used for comparison purposes (Student $t$ test). Multivariate analysis by multiple linear regression was performed to identify independent variables associated with high MLN TNF levels. Variables were entered when they achieved $\mathrm{p}<0.05$ on univariate analysis. A $p$ value of $<0.05$ was required for statistical significance.

\section{RESULTS}

IL-6 mRNA levels in MLN from cirrhotic patients (5.1 (1.8-9.8) copies/ng RNA) were not different from control patients $(2.8(1-6)$ copies/ng RNA) $(p=0.6)$. Also, IL-6 values by EIA were similar between controls (2.6 (1.3-4) pg/mg protein) and patients with liver cirrhosis $(3.4(2.1-4.5) \mathrm{pg} / \mathrm{mg}$ protein) $(\mathrm{p}=0.09)$. In contrast, as shown in fig 2 , both TNF mRNA and TNF levels were significantly higher in cirrhotic patients compared with controls. MLN TNF levels significantly correlated with blood TNF levels $(r=0.56, p=0.002)$. According to these results, tissue TNF expression was high in all cirrhotic patients examined (score 3 in $>50 \%$ of mononuclear cells) while it was very low in controls (score $0-1$ in $<10 \%$ of cells) (fig 3). Double immunostaining demonstrated that macrophages were the main cells responsible for this TNF production. In the 13 cirrhotic patients in which MLN and hepatic LN were simultaneously obtained, TNF levels were significantly higher in MLN (35 (19-49) pg/mg protein) compared with levels found in hepatic LN (13 (10-16) pg/mg protein) $(\mathrm{p}=0.001)$.

Among the different clinical, biochemical, and haemodynamic variables analysed, we observed that TNF values in 


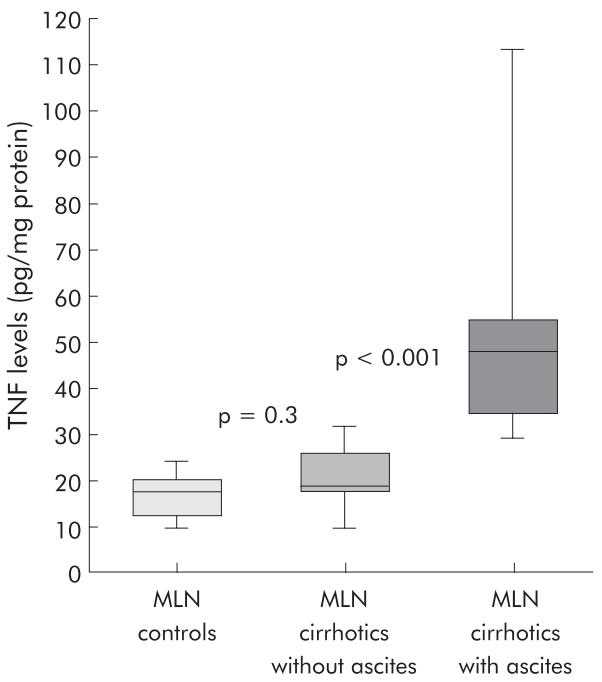

Figure 4 Comparison of tumour necrosis factor $\alpha$ (TNF) levels in mesenteric lymph nodes (MLN) from controls and cirrhotic patients with or without ascites.

MLN from cirrhotic patients who presented with ascites at the time of surgery were much more elevated than TNF values found in MLN from cirrhotics without ascites (fig 4). In fact, cirrhotic patients without ascites were not different from control patients with respect to TNF levels. In contrast, cirrhotic patients classified according to Child-Pugh status did not show statistically different levels of TNF in MLN (data not shown). Also, patients with cirrhosis who were receiving $\beta$-blocker or norfloxacin therapy had similar MLN TNF levels compared with patients who were not taking such medications (data not shown).

To further explore the significance of increased MLN TNF production in cirrhotic patients, we divided patients into two groups of low and high MLN TNF levels using $28 \mathrm{pg} / \mathrm{mg}$ protein (median value) as the cut off point (table 1). As shown, elevated MLN TNF levels were associated with a higher ChildPugh score, the antecedent of ascites, a lower prothrombin ratio, higher bilirubin values and plasma TNF levels, and increased synthesis of TNF mRNA. Although not statistically different, patients with high MLN TNF values had a tendency to show more haemodynamic disturbances (higher cardiac index and portal pressure). The strongest association was with the presence of ascites at the time of transplantation; this was confirmed in the multivariate analysis as ascites was the only independent predictive factor for elevated MLN TNF levels (table 1). In addition, bacterial infections during the first month postransplant were only detected in the group of patients with high MLN TNF levels (table 1). These five infections corresponded to one urinary tract infection (E faecalis), one episode of sepsis ( $C$ freundi), one bacterial pneumonia, and two wound infections (S aureus, E faecalis).

\section{DISCUSSION}

This study clearly demonstrated that there was increased TNF production in the MLN of patients with liver cirrhosis. This augmented TNF production appeared to be specific for MLN rather than a general phenomenon of LN from cirrhotic patients, as indicated by low TNF levels in hepatic LN. Our observations are in accordance with experimental data in which a significant elevation in local TNF concentrations was observed in cirrhotic rats with ascites. ${ }^{10}$

The reason for this augmented TNF production in the MLN of cirrhotic patients could be bacterial translocation from the intestinal lumen to the MLN. Bacterial antigens and endotoxins are potent stimulators of TNF release by mononuclear cells. ${ }^{7}$ This relationship between TNF production and bacterial translocation was supported in our study by the observed association of high TNF levels in MLN from patients with advanced liver failure and more importantly with the presence of ascites, as both factors seem to correlate with bacterial translocation in the only study performed in human cirrhosis. ${ }^{13}$ It is also known that ascites in the context of portal hypertension may contribute in altering intestinal permeability and therefore facilitating bacterial crossing of the intestinal wall. ${ }^{14}$ Additional data from experimental studies also support this. Cirrhotic rats need to develop ascites in order to present efficient bacterial translocation, ${ }^{15}$ and when bacteria translocate in MLN, local TNF production is substantially increased. ${ }^{10}$ The increased incidence of bacterial infections in the postransplant period in our transplanted patients

Table 1 Clinical, haemodynamic, and biochemical differences between cirrhotic patients with low and high tumour necrosis factor $\alpha$ (TNF) levels in mesenteric lymph nodes

\begin{tabular}{|c|c|c|c|}
\hline & $\begin{array}{l}\text { Low TNF levels }(<28 \\
\mathrm{pg} / \mathrm{mg})(\mathrm{n}=11)\end{array}$ & $\begin{array}{l}\text { High TNF levels (>28 } \\
\mathrm{pg} / \mathrm{mg})(\mathrm{n}=15)\end{array}$ & $\mathrm{p}$ Value \\
\hline Age $(y)$ & $55 \quad(12)$ & 52 (10) & NS \\
\hline Sex (male) & $4 \quad(36 \%)$ & 11 (73) & NS \\
\hline Child-Pugh C & $2 \quad(18 \%)$ & $8 \quad(53 \%)$ & NS \\
\hline Child score & $7.3(1.8)$ & 10 (2.7) & $0.01 *$ \\
\hline Prior ascites & $4 \quad(36 \%)$ & $13 \quad(86 \%)$ & $0.01 *$ \\
\hline Ascites & 0 & 13 (86\%) & $<0.001$ * \\
\hline Albumin (mg/dl) & $2.9(0.7)$ & $2.5(0.6)$ & NS \\
\hline Bilirrubin (mg/dl) & $2.2(1.4)$ & $4.5(3.1)$ & 0.04 * \\
\hline Prothrombin ratio $(\%)$ & 61 (19) & 47 (16) & $0.04^{*}$ \\
\hline Mean arterial pressure $(\mathrm{mm} \mathrm{Hg})$ & 71 (15) & 68 (13) & NS \\
\hline Cardiac index $\left(1 / \mathrm{minm}^{2}\right)$ & $3.9(1.6)$ & $4.4(1.8)$ & 0.06 \\
\hline $\begin{array}{l}\text { Systemic vascular resistance index } \\
\left(\text { dyne } \times \mathrm{s} / \mathrm{cm}^{5} / \mathrm{m}^{2}\right)\end{array}$ & 1485 (254) & 1192 (111) & 0.07 \\
\hline Portal pressure (mm Hg) & 23 (4) & $27 \quad(6)$ & 0.07 \\
\hline$\beta$-blocker therapy & $5 \quad(45 \%)$ & $7 \quad(46 \%)$ & NS \\
\hline Norfloxacin therapy & $3 \quad(27 \%)$ & $6 \quad(40 \%)$ & NS \\
\hline Bacterial postransplant infection & 0 & $5 \quad(33 \%)$ & $0.05^{*}$ \\
\hline TNF mRNA (copies/ng RNA) & $44 \quad(32)$ & 104 (128) & 0.03 \\
\hline Blood TNF (pg) & $20.5(13)$ & $40.3(20.8)$ & 0.01 * \\
\hline
\end{tabular}

Values are mean (SD) or number (\%).

*Variables included in the multiple linear regression $\left(r^{2}=0.56, F=3.27, p=0.02\right)$. Ascites was the only independent variable (coefficient $=0.483, p=0.005$ ). 
with high MLN TNF levels may also be interpreted as favouring augmented bacterial translocation in these patients. As the postulated mechanism for bacterial infections in cirrhotics, namely spontaneous bacterial peritonitis, is bacterial translocation followed by secondary bacteraemia and local infection, ${ }^{16}$ one is tempted to speculate that the same scheme could be applied to our transplanted patients with bacterial infections. In that case, high MLN TNF production would be a surrogate marker of bacterial translocation. The fact that three of the four bacteria isolated in these postransplant infections were of enteric origin would also support this hypothesis.

What are the consequences of this increased TNF production in the MLN? TNF has been implicated in the typical haemodynamic alterations of liver cirrhosis. Blood TNF levels have been found to be elevated in cirrhotic patients and in animal models of cirrhosis. ${ }^{11}{ }^{17}$ Inhibition of TNF production by different approaches in rats with portal hypertension is accompanied by amelioration of the hyperdynamic syndrome and even a decrease in portal pressure. ${ }^{18-20}$ One of the hypotheses explaining the mechanism of action of TNF is a contribution to splanchnic vasodilatation through NO synthesis stimulation. TNF produced in MLN would have a local effect in splanchnic vessels by stimulating generation of NO via eNOS, through upregulation of the synthesis of tetrahydrobiopterin, a cofactor and enhancer of NOS activity. ${ }^{10}$ An alternative pathway for TNF causing increased NO synthesis is stimulation of eNOS phosphorylation (required for its activation) via the PI 3-kinase-Akt signal transduction pathway. ${ }^{22}$ This mechanism has been shown to operate in portal hypertensive gastric mucosa. It is not known whether these mechanisms demonstrated in animal models also occur in human cirrhosis. However, increased eNOS activity in splanchnic vessels and elevated NO levels in portal blood have been demonstrated in patients with liver cirrhosis. ${ }^{23}{ }^{24}$ Our results also suggest that increased MLN TNF production in cirrhotic patients is associated with more haemodynamic alterations. Ascites, an indicator of haemodynamic disturbance, was more frequent in patients with high MLN TNF levels. In addition, patients with elevated MLN TNF levels showed a clear trend towards more altered haemodynamic parameters (cardiac index, systemic vascular resistance, and portal pressure) in comparison with patients with low MLN TNF levels. The limited size of the sample studied probably explains this lack of significance. The observed correlation between TNF levels in MLN and plasma also suggests that this locally produced TNF contributes in part to total circulating TNF.

Another aspect that merits an additional comment is the apparent lack of effect of therapy with $\beta$-blockers or nofloxacin on MLN TNF levels. This may be explained in part by the relatively low number of patients included in the study. $\beta$-Blockers have been reported to reduce bacterial translocation in experimental cirrhosis by slowing intestinal transit. ${ }^{25} \mathrm{It}$ is not known whether it occurs in human cirrhosis. From a theoretical point of view, this effect would decrease local TNF production. On the other hand, the use of selective intestinal decontamination with norfloxacin has been clearly associated with a decrease in bacterial infections in cirrhotic patients. ${ }^{26}{ }^{27}$ In patients treated with norfloxacin, Gram negative bacteria in the faecal flora are markedly reduced. ${ }^{26}$ In addition, in cirrhotic animals, quinolone administration for a short period of time is associated with less Gram negative bacteria in intestinal flora, decreased bacterial translocation, and a low incidence of spontaneous bacterial peritonitis. ${ }^{28}$ We would expect to find lower levels of TNF production in the MLN of cirrhotic patients on norfloxacin prophylaxis. However, it is not less true that quinolone resistant Gram negative bacteria are increasingly found in the stools of cirrhotic patients treated with norfloxacin and bacterial infections in these patients are currently caused by either Gram positive bacteria or quinolone resistant Gram negative bacteria. ${ }^{29-31}$ Moreover, it is not clear whether therapeutic interventions in animal mod- els are always applicable to human cirrhosis. Cirrhotic patients are usually treated with $\beta$-blockers and norfloxacin for long periods of time, while studies in animal models are performed after a short exposure to therapy. The influence of these therapeutic interventions may not be the same in these different situations. We believe that patients with advanced cirrhosis on long term prophylaxis with norfloxacin continue to have bacterial translocation, probably by bacteria resistant to this therapy.

Demonstrating that in advanced human cirrhosis there is bacterial translocation, responsible for increased MLN TNF production causing augmented splanchnic vascular NO release, should have been the final objective of this work. However, we looked at just one piece of the puzzle. Obtaining different human tissues simultaneously is not an easy task. In addition, bacterial translocation is a difficult event to prove: MLN are not easily obtained, bacterial contamination during processing is common, and surgical antibiotic prophylaxis is an unavoidable inconvenience. In our case, antibiotic prophylaxis prior to surgery proved to be an insurmountable problem to efficiently culture MLN. However, we feel that our data suggest that, in common with experimental cirrhosis, in patients with advanced liver cirrhosis, bacterial translocation may also induce local TNF production in MLN.

\section{ACKNOWLEDGEMENTS}

The authors thank all members of the medical and nursing staff of the Liver Transplantation Unit for their enthusiastic collaboration. We also wish to thank Dr Abel Mujal, Dr Alex Smithson, and Moises Martinez for their help. The study was supported in part by grant 97/2118 from the Fondo de Investigaciones Sanitarias, and C03/02 from the Instituto de Salud Carlos III, Spain.

\section{Authors' affiliations}

J Genescà, V Peribáñez, A Gónzalez, L Castells, R Esteban,

Juardia, Liver Unit, Department of Internal Medicine, Hospital Universitari Vall d'Hebron, Universitat Autonoma de Barcelona, Barcelona, Spain

R Martí, F Campos, R Segura, Department of Biochemistry, Hospital Universitari Vall d'Hebron, Universitat Autonoma de Barcelona, Barcelona, Spain

F Rojo, C Ruiz-Marcellán, Department of Pathology, Hospital Universitari Vall d'Hebron, Universitat Autonoma de Barcelona, Barcelona, Spain

C Margarit, Liver Transplantation Unit, Hospital Universitari Vall d'Hebron, Universitat Autonoma de Barcelona, Barcelona, Spain

\section{REFERENCES}

1 Groszmann RJ. Hyperdynamic circulation of liver disease 40 years later: pathophysiology and clinical consequences. Hepatology 1994:20:1359-63.

2 Schrier RW, Arroyo V, Bernardi M, et al. Peripheral arterial vasodilatation hypothesis: a proposal for the initiation of renal sodium and water retention in cirrhosis. Hepatology 1988:8:1151-7.

3 Martin PY, Gines P, Schrier RW. Nitric oxide as a mediator of hemodynamic abnormalities and sodium and water retention in cirrhosis. N Engl J Med 1998;339:533-41

4 Wiest R, Groszmann RJ. Nitric oxide and portal hypertension: its role in the regulation of intrahepatic and splanchnic vascular resistance. Semin Liver Dis 1999;19:411-26.

5 Wiest R, Groszmann RJ. The paradox of nitric oxide in cirrhosis and portal hypertension: too much, not enough. Hepatology 2002;35:478-91.

6 Vallance P, Moncada S. Hyperdynamic circulation in cirrhosis: a role for nitric oxide?. Lancet 1991;337:776-8.

7 Papadakis KA, Targan SR. Tumor necrosis factor: biology and therapeutic inhibitors. Gastroenterology 2000;119:1148-57.

8 Mainous MR, Ertel W, Chaudry IH, et al . The gut: a cytokine-generating organ in systemic inflammation? Shock cytokine-generatin

9 Deitch EA. Role of the gut lymphatic system in multiple organ failure. Curr Opin Crit Care 2001; 7:92-8.

10 Wiest R, Das S, Cadelina G, et al. Bacterial translocation in cirrhotic rats stimulates eNOS-derived NO production and impairs mesenteric vascular contractility. I Clin Invest 1999:104:1223-33.

11 Genesca J, Gonzalez A, Segura R, et al . Interleukin-6, nitric oxide, and the clinical and hemodynamic alterations of patients with liver cirrhosis. Am J Gastroenterol 1999;94:169-77. 
12 Lee FY, Lu RH, Tsai YT, et al. Plasma interleukin-6 levels in patients with cirrhosis. Relationship to endotoxemia, tumor necrosis factor- $\alpha$, and hyperdynamic circulation. Scand J Gastroenterol 1996;31:500-5.

13 Cirera I, Baver TM, Navasa M, et al . Bacterial translocation of enteric organisms in patients with cirrhosis. J Hepatol 2001;34:32-7.

14 Guarner C, Soriano G. Spontaneous bacterial peritonitis. Semin Liver Dis 1997;17:203-17.

15 Garcia-Tsao G, Lee FY, Barden GE, et al. Bacterial translocation to mesenteric lymph nodes is increased in cirrhotic rats with ascites. Gastroenterology 1995;108:1835-41.

16 Such J, Runyon BA. Spontaneous bacterial peritonitis. Clin Infect Dis 1998;27:669-74

17 Chu CJ, Lee FY, Wang SS, et al. Hyperdynamic circulation of cirrhotic rats with ascites: role of endotoxin, tumour necrosis factor-alpha and nitric oxide. Clin Sci (Lond) 1997:93:219-25.

18 López-Talavera JC, Merrill WW, Groszmann RJ. Tumor necrosis factor $\alpha$ : a major contributor to the hyperdynamic circulation in prehepatic portal-hypertensive rats. Gastroenterology 1995; 108:761-7.

19 López-Talavera JC, Cadelina G, Olchowski J, et al. Thalidomide inhibits tumor necrosis factor $\alpha$, decreases nitric oxide synthesis, and ameliorates the hyperdynamic circulatory syndrome in portal-hypertensive rats. Hepatology 1996;23:1616-21.

20 Lopez-Talavera JC, Levitzki A, Martinez M, et al. Tyrosine kinase inhibition ameliorates the hyperdynamic state and decreases nitric oxide production in cirrhotic rats with portal hypertension and ascites. J Clin Invest 1997; 100:664-70

21 Kawanaka H, Jones MK, Szabo IL, et al. Activation of eNOS in rat portal hypertensive gastric mucosa is mediated by TNF-alpha via the $\mathrm{PI}$ 3-kinase-Akt signaling pathway. Hepatology 2002;35:393-402.

22 Iwakiri Y, Tsai MH, McCabe TJ, et al. Phosphorylation of eNOS initiates excessive NO production in early phases of portal hypertension. Am J Physiol Heart Circ Physiol 2002;282:H2084-90.
23 Albornoz L, Motta A, Alvarez D, et al. Nitric oxide synthase activity in the splanchnic vasculature of patients with cirrhosis: relationship with hemodynamic disturbances. J Hepatol 2001;35:452-6.

24 Battista S, Bar F, Mengozzi G, et al. Hyperdynamic circulation in patients with cirrhosis: direct measurement of nitric oxide levels in hepatic and portal veins. J Hepatol 1997;26:75-80.

25 Perez-Paramo M, Muñoz J, Albillos A, et al. Effect of propranolol on the factors promoting bacterial translocation in cirrhotic rats with ascites. Hepatology 2000;31:43-8.

26 Gines P, Rimola A, Planas R, et al. Norfloxacin prevents spontaneous bacterial peritonitis recurrente in cirrhosis: results of a double-blind, placebo-controlled trial. Hepatology 1990;1 2:716-24.

27 Novella $M$, Sola R, Soriano $G$, et al. Continuous versus inpatient prophylaxis of the first episode of spontaneous bacterial peritonitis with norfloxacin. Hepatology 1997;25:532-6.

28 Runyon BA, Borzio M, Young S, et al. Effect of selective bowel decontamination with norfloxacin on spontaneous bacterial, translocation, and survival in an animal model of cirrhosis. Hepatology 1995;21:1719-24.

29 Aparicio JR, Such J, Pascual S, et al. Development of quinolone-resistant strains of Escherichia coli in stools of patients with cirrhosis undergoing norfloxacin prophylaxis: clinical consequences. J Hepatol 1999;31:277-83

30 Fernandez J, Navasa M, Gomez J, et al. Bacterial infections in cirrhosis: epidemiological changes with invasive procedures and norfloxacin prophylaxis. Hepatology 2002;35:140-8.

31 Cereto F, Genesca J, Smithson A, et al. Spontaneous bacterial peritonitis caused by quinolone-resistant Escherichia coli: could steroid therapy play a role? Eur J Gastroenterol Hepatol 2002;14:81-3.

See which articles have just been accepted for publication and preview the table of contents for the next issue a month before it is published

\section{www.gutjnl.com}

